\title{
Risk Factors For Long-Term Survival in Patients With ypN+M0 Rectal Cancer After Radical Anterior Resection
}

\section{Marcin Zeman ( $\sim$ mzeman@wp.pl)}

Maria Sklodowska-Curie National Research Institute of Oncology, Gliwice Branch

\section{Władysław Skałba}

Maria Sklodowska-Curie National Research Institute of Oncology, Gliwice Branch

\section{Piotr Szymański}

Maria Sklodowska-Curie National Research Institute of Oncology, Gliwice Branch

\section{Grzegorz Hadasik}

Maria Sklodowska-Curie National Research Institute of Oncology, Gliwice Branch

\section{Dmytro Żaworonkow}

Maria Sklodowska-Curie National Research Institute of Oncology, Gliwice Branch

\section{Dominik Andrzej Walczak}

Maria Sklodowska-Curie National Research Institute of Oncology, Gliwice Branch

\section{Agnieszka Czarniecka}

Maria Sklodowska-Curie National Research Institute of Oncology, Gliwice Branch

\section{Research Article}

Keywords: angiotensin-converting enzyme inhibitors, lymph node metastasis, lymph node yield, negative lymph node count, rectal cancer, renin-angiotensin system

Posted Date: August 13th, 2021

DOl: https://doi.org/10.21203/rs.3.rs-688551/v1

License: (a) (1) This work is licensed under a Creative Commons Attribution 4.0 International License. Read Full License

Version of Record: A version of this preprint was published at BMC Gastroenterology on March 26th, 2022. See the published version at https://doi.org/10.1186/s12876-022-02226-9. 


\section{Abstract}

Background: Regional lymph node metastases are the main adverse prognostic factor in patients with rectal cancer without distant metastases. There are discrepancies, however, regarding additional risk factors in the group of $\mathrm{ypN}+\mathrm{M} 0$ patients.

The purpose of the study was to assess clinical and pathological factors affecting long-term oncological outcomes in the group of ypN+M0 patients after radical rectal anterior resection.

Methods: 112 patients with ypN+M0 rectal cancer after neoadjuvant therapy and radical anterior resection were subject to a retrospective analysis. The effect of potential factors on survival was assessed with the use of Kaplan-Meier curves together with a log-rank test and multiple factor Cox proportional hazards model.

Results: In the multiple factor Cox analysis, adverse factors affecting OS were: the use of angiotensinconverting enzyme inhibitors (ACEls) (HR: 3.059, 95\% Cl: 1.349-6.934, $p=0.007$ ) and past $<=3$ cycles of adjuvant chemotherapy (HR: $2.833,95 \% \mathrm{Cl}: 1.289-6.229, \mathrm{p}=0.01$ ). For DFS, significant adverse factors were: the use of ACEls (HR: $3.11,95 \% \mathrm{Cl}: 1.01-9.56, p=0.047)$, presence of perineural invasion (HR: 7.27, 95\% Cl: 2.74-19.3, $\mathrm{p}<0.001$ ) and occurrence of postoperative complications (HR: 6.79, 95\% Cl: 2.09-22.11, $\mathrm{p}=0.001$ ), while a positive factor was the negative lymph node (NLN) count $>7$ (HR: $0.33,95 \%$ Cl: $0.12-$ $0.88, p=0.026)$.

Conclusions: The use of ACEls may have a negative effect on long-term treatment outcomes in patients with ypN+M0 rectal cancer. In this group of patients, the NLN count seems to be an important prognostic factor, as well.

\section{Background}

Regional lymph node metastases are the main adverse prognostic factor in patients with colorectal cancer without distant metastases. [1] However, reports on the risk factor of long-term survival in the group ypN + are not consistent. It turns out that the assessment of nodal staging according to the TNM classification does not clearly stratify subjects after neoadjuvant therapy with regard to long-term survival. [2] Therefore, attempts have been made to assess other factors, such as lymph node ratio (LNR), log odds of positive nodes (LODDS), positive lymph nodes (PLN), or negative lymph nodes (NLN). Their prognostic value, however, has not been finally established. [1,3] A separate issue is the minimum lymph node yield (LNY), owing to which underestimation of nodal staging may be avoided. Some authors deny the adverse effect of low LNY on survival, and even suggest that it is related to a good response to neoadjuvant therapy. [4] So far, the effect of comorbidities and the medication used therein, such as metformin or renin-angiotensin system inhibitors (RASI), on the treatment outcomes has not been clarified. [5, 6] There are few publications on this issue. It has also been shown that postoperative complications, especially anastomotic leakage (AL) after rectal anterior resection (AR) may have a significant effect on survival. [7] 
The purpose of the study was a retrospective assessment of clinical and pathological factors affecting long-term oncological outcomes in patients with rectal cancer at ypN $+\mathrm{M} 0$, after neoadjuvant therapy and radical (RO) AR.

\section{Methods}

\section{Patients}

A retrospective analysis was performed on 112 patients with ypN + M0 rectal cancer post neoadjuvant therapy and radical (R0) AR, treated at the National Research Institute of Oncology in Gliwice in 20082016. The process of the study group formation in presented on the chart in Fig. 1.

Patient characteristics is presented in Table 1. Comorbidities were assessed separately, as well as on the basis of the Charlson comorbidity index (CCl). [8] Distant metastases were considered synchronous if occurred up to 3 months after surgery. 
Table 1

Patient characteristics

\begin{tabular}{|c|c|c|}
\hline \multirow[t]{2}{*}{ Variable } & & \multirow{2}{*}{$\begin{array}{l}\mathrm{n}(\%) \\
\text { mean (SD)* }\end{array}$} \\
\hline & & \\
\hline \multirow[t]{2}{*}{ Sex } & Females & $42(37.5)$ \\
\hline & Males & $70(62.5)$ \\
\hline Age (years) & & $62,21(10.32)^{*}$ \\
\hline BMI $\left(\mathrm{kg} / \mathrm{m}^{2}\right)$ & & $26,64(5.05)^{\star}$ \\
\hline CAD & & $5(4.5)$ \\
\hline $\mathrm{AH}$ & & $45(40.2)$ \\
\hline DIAB & & $18(16.1)$ \\
\hline $\mathrm{CCl}>2$ & & $25(22.3)$ \\
\hline Alpha-blockers & & $3(2.7)$ \\
\hline Beta-blockers & & $26(23.2)$ \\
\hline ACEls & & $19(17)$ \\
\hline Calcium channel blockers & & $14(12.5)$ \\
\hline Diuretics & & $10(8.9)$ \\
\hline ARBs & & $9(8)$ \\
\hline Metformin & & $7(6.2)$ \\
\hline Glimepiride & & $7(6.2)$ \\
\hline Gliclazide & & $5(4.5)$ \\
\hline \multirow[t]{4}{*}{ cT } & 1 & $1(0.9)$ \\
\hline & 2 & $10(8.9)$ \\
\hline & 3 & $99(88.4)$ \\
\hline & 4 & $2(1.8)$ \\
\hline
\end{tabular}

*continuous variable, $\mathrm{BMI}$ - body mass index, $\mathrm{CAD}$ - coronary artery disease, $\mathrm{AH}$ - arterial hypertension, DIAB- diabetes mellitus, CCl- Charlson comorbidity index, ACEls- angiotensin-converting enzyme inhibitors, ARBs- angiotensin receptor blockers, CRT- chemoradiotherapy, RT- radiotherapy, Time RT-Stime from radiotherapy completion to surgery, AL- anastomotic leakage, $\mathrm{G}$ - histological tumour grade, TRG- tumour regression grade, PLN- positive lymph nodes, NLN- negative lymph nodes, LNY- lymph node yield, LNR- lymph node ratio, LODDS- log odds of positive lymph nodes, ENE- extranodal extension, LVI- lymphovascular invasion, PNI- perineural invasion, CT- chemotherapy, SD- standard deviation 


\begin{tabular}{|c|c|c|}
\hline \multicolumn{2}{|l|}{ Variable } & \multirow{2}{*}{$\begin{array}{l}n(\%) \\
\text { mean (SD)* }\end{array}$} \\
\hline & & \\
\hline $\mathrm{cN}+$ & & $91(81.2)$ \\
\hline \multirow[t]{3}{*}{ Distance from the anal verge $(\mathrm{cm})$} & $0-5$ & $42(37.5)$ \\
\hline & $6-10$ & $52(46.4)$ \\
\hline & $11-15$ & $18(16.1)$ \\
\hline \multirow[t]{2}{*}{ Neoadjuvant } & CRT & $27(24.1)$ \\
\hline & RT & $85(75.9)$ \\
\hline Time RT-S > 6 weeks & & $45(40.2)$ \\
\hline Loop ileostomy & & $23(20.5)$ \\
\hline \multirow[t]{3}{*}{ Complications (Clavien-Dindo) } & 0 & $73(65.2)$ \\
\hline & $1-2$ & $14(12.5)$ \\
\hline & $>2$ & $25(22.3)$ \\
\hline \multirow[t]{3}{*}{$A L$} & Early AL & $16(14.3)$ \\
\hline & Late AL & $7(6.2)$ \\
\hline & No leakage & $89(79.5)$ \\
\hline \multirow[t]{4}{*}{ ypG } & 1 & $5(4.5)$ \\
\hline & 2 & $82(73.2)$ \\
\hline & 3 & $8(7.1)$ \\
\hline & $\mathrm{x}$ & $17(15.2)$ \\
\hline \multirow[t]{3}{*}{ урт } & 0 & $1(0.9)$ \\
\hline & 2 & $20(17.9)$ \\
\hline & 3 & $91(81.2)$ \\
\hline TRG & $0-1$ & $27(24.1)$ \\
\hline
\end{tabular}

${ }^{*}$ continuous variable, $\mathrm{BMI}$ - body mass index, $\mathrm{CAD}$ - coronary artery disease, $\mathrm{AH}$ - arterial hypertension, DIAB- diabetes mellitus, $\mathrm{CCl}$ - Charlson comorbidity index, ACEls- angiotensin-converting enzyme inhibitors, ARBs- angiotensin receptor blockers, CRT- chemoradiotherapy, RT- radiotherapy, Time RT-Stime from radiotherapy completion to surgery, AL- anastomotic leakage, $\mathrm{G}$ - histological tumour grade, TRG- tumour regression grade, PLN- positive lymph nodes, NLN- negative lymph nodes, LNY- lymph node yield, LNR- lymph node ratio, LODDS- log odds of positive lymph nodes, ENE- extranodal extension, LVI- lymphovascular invasion, PNI- perineural invasion, CT- chemotherapy, SD- standard deviation 


\begin{tabular}{|c|c|c|}
\hline \multirow[t]{2}{*}{ Variable } & & $\begin{array}{l}n(\%) \\
\text { mean (SD)* }\end{array}$ \\
\hline & $2-3$ & 85 (75.9) \\
\hline \multicolumn{2}{|l|}{ Mucinous component } & $6(5.4)$ \\
\hline \multicolumn{2}{|l|}{ Tumour deposits } & $29(25.9)$ \\
\hline \multicolumn{2}{|l|}{ PLN count } & $3,59(3.75)^{\star}$ \\
\hline \multicolumn{2}{|l|}{ NLN count } & $10,69(6.16) \star$ \\
\hline \multicolumn{2}{|l|}{ LNY } & $13,99(6.79) \star$ \\
\hline \multirow[t]{2}{*}{ ypN } & 1 & $79(70.5)$ \\
\hline & 2 & $33(29.5)$ \\
\hline \multicolumn{2}{|l|}{ LNR } & $0,26(0.21)^{*}$ \\
\hline \multicolumn{2}{|l|}{ LODDS } & $-1,3(1.18)^{*}$ \\
\hline \multicolumn{2}{|l|}{ ENE } & $14(12.5)$ \\
\hline \multicolumn{2}{|l|}{ LVI } & $10(8.9)$ \\
\hline \multicolumn{2}{|l|}{ PNI } & $13(11.6)$ \\
\hline \multicolumn{2}{|l|}{ Distal margin (cm) } & $2,11(1.61)^{\star}$ \\
\hline \multicolumn{2}{|l|}{ Adjuvant CT } & $89(79.5)$ \\
\hline \multicolumn{2}{|l|}{ Adjuvant CT > 3 cycles } & $78(69.6)$ \\
\hline \multicolumn{3}{|c|}{$\begin{array}{l}\text { *continuous variable, BMI- body mass index, CAD- coronary artery disease, AH- arterial hypertension, } \\
\text { DIAB- diabetes mellitus, CCI- Charlson comorbidity index, ACEls- angiotensin-converting enzyme } \\
\text { inhibitors, ARBs- angiotensin receptor blockers, CRT- chemoradiotherapy, RT- radiotherapy, Time RT-S- } \\
\text { time from radiotherapy completion to surgery, AL- anastomotic leakage, G- histological tumour grade, } \\
\text { TRG- tumour regression grade, PLN- positive lymph nodes, NLN- negative lymph nodes, LNY- lymph } \\
\text { node yield, LNR- lymph node ratio, LODDS- log odds of positive lymph nodes, ENE- extranodal } \\
\text { extension, LVI- lymphovascular invasion, PNI- perineural invasion, CT- chemotherapy, SD- standard } \\
\text { deviation }\end{array}$} \\
\hline
\end{tabular}

\section{Procedures}

All the patients received neoadjuvant therapy: radiotherapy (RT) at a total dose of 25-42 Gy or chemotherapy (CRT) at a dose of 42-54 Gy combined with one or two cycles of chemotherapy based on 5-fluorouracil. Before surgery, mechanical bowel preparation was performed with the administration of an oral antibiotic and perioperative intravenous antibiotic prophylaxis. AR was performed using laparotomy with total mesorectal excision. End-to-end anastomosis of bowel was performed with a circular stapler. $\mathrm{AL}$, in accordance with the International Study Group of Rectal Cancer, was defined as a deficit at the 
anastomotic site leading to a communication between the intra- and extraluminal compartments and/or presence of pelvic abscess near the anastomosis. [9] AL was qualified as early if diagnosed within 30 days of surgery, and as late if occurred after that time. Adjuvant treatment was based on 5 -fluorouracil. The histopathological examination was based on standard methods of searching for lymph nodes in the surgical specimen. Tumour regression grade (TRG) was based on the assessment of the degree of fibrosis compared to the residual tumor tissue and ranged from 0 to 3, i.e. 0 (complete response), 1 (< $10 \%$ residual tumor), $2(10-50 \%)$ and $3(>50 \%)$.

\section{Variables}

Staging was assessed on the basis of the American Joint Committee on Cancer, TNM Staging System, 8th edition, 2017. LNR was calculated as the PLN to LNY ratio, while LODDS was calculated with the formula $\ln [(P L N$ count $) /(N L N$ count)]. In the LODDS and LNR analysis in ypN1c patients, the PLN count was treated as no data and was excluded from this part of the analysis. Additional potential risk factors subject to analysis included: age, sex, body mass index (BMI), presence of comorbidities, $\mathrm{CCl}$, medications used, type of neoadjuvant therapy (RT vs. CRT), time from RT completion to surgery, clinical staging of the disease before treatment, tumour distance from the anal verge, presence of loop ileostomy, occurrence of postoperative complications, TRG, perineural invasion (PNI), lymphovascular invasion (LVI), extranodal extension (ENE), width of distal margin, adjuvant chemotherapy.

\section{Statistical methods}

The effect of potential factors on survival was assessed with the use of Kaplan-Meier curves together with a log-rank test and Cox proportional hazards model. The estimation of cut-off points for the parameters related to nodal staging was based on the analysis of Kaplan-Meier curve difference significance for iteratively increased cut-off thresholds. All calculations were made using the statistical package $\mathrm{R}$ version 3.5.3.

\section{Results}

In the study group, 3- and 5-year overall survival (OS) was $80.4 \%$ and $67 \%$, disease-free survival (DFS) was $71.9 \%$ and $59.7 \%$, and disease-specific survival (DSS) was $85.5 \%$ and $74.4 \%$, respectively. The mean follow-up period in the study group was 57 months. 30-day mortality after surgery was $1.7 \%$. Loop ileostomy during the primary procedure was created in $23 / 112(20.5 \%)$ of patients. Postoperative complications were observed in 39/112 (34.8\%) of patients. AL was observed in $23 / 112(20.5 \%)$ of patients, including 16/23 (69.6\%) early and 7/23 (30.4\%) late ALs. In 15/23 (65.2\%) cases of AL, anastomosis was separated by performing the Hartmann's procedure. Aside to the above, abnormal wound healing was observed in 6 patients, and there were 3 cases of urinary tract infection, 3 cases of pneumonia, 3 cases of bleeding and 1 case of mechanical obstruction. 19 (17\%) patients used angiotensin-converting enzyme inhibitors (ACEls) at the time of treatment initiation, with 5 patients using ramipril, 5 perindopril, 3 enalapril, 2 lisinopril, 2 trandolapril, 1 cilazapril and 1 imidapril. 9 (8\%) patients used angiotensin receptor blockers (ARBs). 


\section{Analysis of nodal staging parameters}

For the LNY variable, no cut-off point for which Kaplan-Meier curves would significantly differ was found. Similarly, no differences in survival were found while comparing nodal staging (ypN1 vs. ypN2) according to the TNM classification. For the PLN count, significant differences in survival were found only at the cut-off point 11 ( $<=11 \mathrm{vs}$. $>11$ ) for OS and DSS $(p=0.016$ and $p=0.03$, respectively), and at the cut-off point for 10 ( $<=10$ vs. $>10)$ for DFS $(p=0.033)$. For the NLN count, significant differences in survival were achieved for the cut-off point $5(<=5$ vs. $>5)$ for OS and DSS $(p=0.0056$ and $p=0.0045$,) and the cut-off point 7 ( $<=7$ vs. $>7$ ) for DFS ( $p=0.029$ ) (Fig. $2 A, B, C)$. For LNR, significant differences in survival were shown for the cut-off point 0.4 ( $<=0.4$ vs. $>0.4)$ for OS $(p=0.019)$, for the cut-off point $0.3(<=0.3$ vs. $>0.3)$ for DFS $(p=0.049)$, and for the cut-off point $0.15(<=0.15$ vs. $>0.15)$ for DSS $(p=0.042)$

(Fig. 2D, E, F). For LODDS, significant differences in survival were achieved for the cut-off point $-0.4(<=$ -0.4 vs. $>-0.4)$ for OS $(p=0.019)$, for the cut-off point $-1(<=-1$ vs $>-1)$ for DFS $(p=0.048)$, and for the cut-off point $-1.6(<=-1.6$ vs. $>-1.6)$ for DSS $(p=0.028)$ (Fig. $2 G, H, I)$.

\section{Single-factor analysis of survival}

No effect of comorbidities on survival was observed, both with regard to separate analysis, and that based on CCI. However, an adverse effect on OS of the use of such medication as ACEls $(p<0.0001)$ (Fig. 3A), calcium channel blockers $(p=0.027)$ and metformin $(p=0.021)$ was shown in the log-rank test. Our analysis also revealed that OS was adversely affected by the occurrence of complications, regardless of the degree in the Clavien-Dindo classification ( $p=0.0087)$, occurrence of $A L(p=0.0026)$, and after dividing $A L$ into early and late, by early $A L(p<0.0001)$. A positive effect on OS was shown with regard to adjuvant chemotherapy $(p=0.016)$, regardless of the number of cycles administered, and also chemotherapy $>3$ cycles $(p=0.0016)$. Age $>65$ years $(p=0.0045)$ was also a significant risk factor for OS.

A negative effect of the use of ACEls ( $p=0.04)$ (Fig. 3B) and metformin $(p=0.048)$, and a positive effect of the use of ARBs ( $p=0.042)$ (Fig. 3D) on DFS was shown. In addition, a negative effect of the occurrence of complications, regardless of the degree in the Clavien-Dindo classification $(p=0.012)$, occurrence of $A L(p=0.024)$, and after dividing $A L$ into early and late, of early $A L(p=0.0095)$ on DFS was shown. Histological grade G3 $(p=0.02)$ and the presence of PNI $(p=0.00015)$ had a negative effect on DFS, as well.

The DSS analysis showed an adverse effect of the use of ACEls $(p=0.003)$ (Fig. 3C), metformin $(p=$ 0.016), occurrence of complications, regardless of the degree in the Clavien-Dindo classification $(p=$ 0.025), occurrence of $A L(p=0.0049)$, and after dividing $A L$ into early and late, of early $A L(p=0.00027)$, and histological grade G3 $(p=0.018)$. No effect of other analysed factors on survival was revealed.

\section{Multiple factor Cox analysis}


The results of multiple factor Cox analysis are shown in Table 2. It was shown that factors having a negative effect on OS were: the use of ACEls (HR: 3.059, 95\% Cl: 1.349-6.934, p = 0.007) and receiving < $=3$ cycles of adjuvant chemotherapy (HR: $2.833,95 \% \mathrm{Cl}: 1.289-6.229, \mathrm{p}=0.01)$. For DFS, significant adverse factors were: the use of ACEls (HR: $3.11,95 \% \mathrm{Cl}: 1.01-9.56, p=0.047)$, presence of PNI (HR: 7.27, $95 \% \mathrm{Cl}: 2.74-19.3, \mathrm{p}<0.001)$, and the occurrence of postoperative complications (HR: $6.79,95 \% \mathrm{Cl}$ : 2.09-22.11, $p=0.001$ ). And a positive factor was the NLN count $>7$ (HR: $0.33,95 \% \mathrm{Cl}: 0.12-0.88, p=$ 0.026). In the DSS analysis, an adverse factor was the use of ACEls (HR: $4.275,95 \%$ Cl: $1.44-12.694, p=$ 0.009 ), while a positive effect was caused by NLN> 5 (HR: $0.22,95 \% \mathrm{Cl}: 0.082-0.586, \mathrm{p}=0.002)$. The other analysed factors were not significant in the multiple factor analysis. 
Table 2

Multiple factor Cox regression model

\begin{tabular}{|c|c|c|c|}
\hline Variables & HR & $95 \% \mathrm{Cl}$ & p \\
\hline \multicolumn{4}{|l|}{ OS } \\
\hline Age $>65$ years & 2.05 & $0.95-4.43$ & 0.069 \\
\hline $\mathrm{CCl}$ & 0.93 & $0.39-2.22$ & 0.865 \\
\hline Metformin & 0.90 & $0.21-3.84$ & 0.891 \\
\hline ACEls & 3.06 & $1.35-6.93$ & 0.007 \\
\hline Calcium channel blockers & 1.80 & $0.66-4.95$ & 0.252 \\
\hline$N L N>5$ & 0.45 & $0.19-1.10$ & 0.080 \\
\hline LNR $>0.4$ & 1.05 & $0.44-2.55$ & 0.910 \\
\hline PLN > 11 & 1.69 & $0.41-6.95$ & 0.468 \\
\hline Complications & 2.01 & $0.70-5.71$ & 0.192 \\
\hline Adj CT < = 3cycles & 2.83 & $1.29-6.23$ & 0.010 \\
\hline \multicolumn{4}{|l|}{ DFS } \\
\hline Metformin & 0.85 & $0.22-3.26$ & 0.808 \\
\hline ACEls & 3.11 & $1.01-9.56$ & 0.047 \\
\hline PLN > 10 & 0.76 & $0.20-2.95$ & 0.692 \\
\hline LNR > 0.3 & 1.20 & $0.25-5.84$ & 0.821 \\
\hline LODDS > -1 & 1.25 & $0.29-5.51$ & 0.766 \\
\hline NLN $>7$ & 0.33 & $0.12-0.88$ & 0.026 \\
\hline Complications & 6.79 & $2.09-22.11$ & 0.001 \\
\hline ypG 3 & 0.75 & $0.13-4.21$ & 0.748 \\
\hline $\mathrm{PNI}$ & 7.27 & $2.74-19.30$ & $<0.001$ \\
\hline \multicolumn{4}{|l|}{$D S S$} \\
\hline NLN > 5 & 0.22 & $0.08-0.59$ & 0.002 \\
\hline LODDS > -1,6 & 0.97 & $0.12-7.98$ & 0.975 \\
\hline \multicolumn{4}{|c|}{$\begin{array}{l}\text { HR- hazard ratio, Cl-confidence interval, OS- overall survival, DFS- disease-free survival, DSS- disease } \\
\text { specific survival, CCl- Charlson comorbidity index, ACEls- angiotensin-converting enzyme inhibitors, } \\
\text { PLN-positive lymph nodes, NLN- negative lymph nodes, LNR- lymph node ratio, LODDS- log odds of } \\
\text { positive lymph nodes, G- histological tumour grade, PNI- perineural invasion, Adj CT- adjuvant } \\
\text { chemotherapy }\end{array}$} \\
\hline
\end{tabular}




\begin{tabular}{|c|c|c|c|}
\hline Variables & HR & $95 \% \mathrm{Cl}$ & p \\
\hline LNR > 0.15 & 1.15 & $0.13-10.19$ & 0.899 \\
\hline PLN > 11 & 2.65 & $0.45-15.44$ & 0.280 \\
\hline Metformin & 1.42 & $0.32-6.22$ & 0.644 \\
\hline ACEls & 4.28 & $1.44-12.69$ & 0.009 \\
\hline Complications & 2.18 & $0.47-10.07$ & 0.317 \\
\hline ypG 3 & 2.82 & $0.69-11.52$ & 0.149 \\
\hline \multicolumn{4}{|c|}{$\begin{array}{l}\text { HR- hazard ratio, Cl- confidence interval, OS- overall survival, DFS- disease-free survival, DSS- disease } \\
\text { specific survival, CCI- Charlson comorbidity index, ACEls- angiotensin-converting enzyme inhibitors, } \\
\text { PLN-positive lymph nodes, NLN- negative lymph nodes, LNR- lymph node ratio, LODDS- log odds of } \\
\text { positive lymph nodes, G- histological tumour grade, PNI- perineural invasion, Adj CT- adjuvant } \\
\text { chemotherapy }\end{array}$} \\
\hline
\end{tabular}

\section{Discussion}

Reports on the effect of $A L$ on long-term survival are not consistent. $[7,10]$ The negative effect of early $A L$ on survival shown in the single-factor analysis was not confirmed by the multiple factor Cox analysis. We have shown, however, a negative effect of postoperative complications on DFS, regardless of the degree in the Clavien-Dindo classification. Similar conclusions were drawn by Sprenger et al, who showed that the occurrence of any surgical complications (anastomotic leakage and/or abnormal wound healing) had a significant negative effect on OS and local recurrence free survival among the patients of the German Rectal Cancer Trial, as shown by a multiple factor analysis. [11] Possible mechanisms underlying the effect of complications on long-term oncological outcomes include no or delayed adjuvant therapy. [12] In a post hoc analysis we showed that the patients with complications significantly more often failed to receive $>3$ cycles of adjuvant chemotherapy, which could suggest that such a claim is correct. In a multiple factor analysis, however, we confirmed the reports of no positive effect on DFS and DSS of adjuvant fluoropyrimidine-based chemotherapy used in the analysed period. $[13,14]$ On the other hand, we showed its positive effect on OS in the case of at least 4 full cycles.

ACEls and ARBs are widely used medications in the treatment of arterial hypertension. Their basic mechanism of action is to block the renin-angiotensin system, which, through AT1 receptor, directly causes vasoconstriction and sodium reabsorption in the renal proximal tubule, and, through AT2 receptor, stimulates aldosterone secretion from the adrenal cortex. [15] It was observed that the use of these medications may reduce the risk of certain neoplasms, and also have a positive effect on neoplasm treatment outcomes. The mechanism of such action includes inhibition of At1-induced angiogenesis and modulation of the immune system in the tumour environment. Expression of RAS components was revealed in all types of cells in the neoplastic tumour microenvironment. [16] At the same time, however, ACEls show an effect on the kallikrein-kinin system (KKS), inhibiting the process of kinin degradation to inactive peptides. Thus, the use of ACEls, unlike of ARBs, results in an increased concentration of kinins, 
which are considered to be pro-tumour peptides. [17] A murine model has revealed that human colorectal cancer cell lines show high expression of both types of bradykinin receptors (B1R and B2R), and their block results in tumour volume reduction, increased apoptosis and inhibition of angiogenesis in vivo. [18] Due to two-way activity of ACEls, their antitumour effect related to the impact on RAS may be diminished by the impact on KKS.

There are few reports on the effect of ACEls or ARBs on treatment outcomes in patients with rectal cancer. Typically, publications discuss subjects with colorectal cancer. Additionally, the effect of both these groups of medications is assessed jointly, which may significantly affect the results and cause conflicting conclusions. A few population studies and the latest meta-analysis have shown a protective effect of ACEls/ARBs on the development of colorectal cancer. $[19,20]$ There are also reports, however, of no such correlation[21], or, in the case of a more detailed analysis, limitation of its influence only to ACEls in the group aged below 65 years, with significant intensity of the protective effect in the proximal colon. [22] The effect of these drugs on the rectal cancer response to neoadjuvant treatment is unclear, too. Morris et al. showed that the use of ACEIs/ARBs significantly increases the frequency of complete responses after preoperative radiotherapy in a multiple factor analysis, [6] while Rombouts et al. did not confirm in their study a positive effect of these drugs. [23] Similar discrepancies exist regarding the assessment of the ACEls/ARBs effect on long-term survival. Ozawa et al. showed a positive effect of ACEIs/ARBs on DFS in the course of left-sided colorectal cancer and stage I cancer. [24] Most authors, however, did not show an effect of these drugs on long-term oncological outcomes. $[6,25,26]$ In the group of patients receiving ARBs, we achieved significantly better DFS as compared with patients who did not receive ARBs, including those receiving ACEls. This parameter, however, was not significant in the multiple factor Cox analysis, most probably due to a small number of patients receiving ARBs. We have shown a negative effect of ACEls on survival both in single- and multiple factor analysis, without showing an effect of comorbidities, analysed both separately and based on $\mathrm{CCl}$. To the best of our knowledge, the effect of ACEls has not been assessed so far exclusively in the group of subjects with ypN + rectal cancer. The analysis results point to a need of further studies in this group of patients. Taking into account a different effect of ACEls and ARBs on long-term oncological outcomes, despite the fact that both these groups of drugs block RAS, it seems reasonable to analyse the effect of these drugs separately. Such approach seems to be justified also because of their different mechanisms of action, including no direct effect of ARBs on KKS.

We have not shown an effect of LNY on survival. Therefore, no understaging occurred in the study group, regardless of the LNY value. The results of our analysis seem to confirm the hypothesis of low LNY being the result of response to neoadjuvant therapy, instead of improper surgical or histopathological technique. $[4,27]$ We have also revealed no differences in survival for nodal staging according to the TNM classification (ypN1 vs ypN2), while the differences in survival based on PLN count were only observed at >10, i.e. much above the N1/N2 threshold in the TNM classification. Nevertheless, the differences turned out to be insignificant in the multiple factor analysis, which may indicate a lack of effect of the PLN count on the prognosis in the study group of patients. The multiple factor analysis has also shown no significant effect of the LNR and LODDS parameters, which account for the PLN count. 
The only parameter related to lymph nodes which in our analysis had a significant effect on survival was the NLN count in the surgical specimen, which is confirmed by observations of several authors. $[3,28]$ There have been promising attempts, yet requiring validation, to modify the current AJCC classification by adding the NLN count parameter. [29] This effect is explained by some authors by the presence of small (up to $2 \mathrm{~mm}$ ) lymph nodes containing micrometastases which are not detected in standard HE staining and for that reason are assessed as NLN by pathologists. It is believed that an increased NLN count may reduce the risk of their non-removal, and, as a result, disease relapse. [30] Another possible explanation is an increase in the NLN count resulting from a stronger immune response to the tumour, with accompanying reactive lymph node enlargement. This phenomenon has a positive prognostic value and facilitates finding a higher number of lymph nodes in the specimen. [31, 32]

The analysis has typical limitations of retrospective and single-centre analyses. The neoadjuvant treatment was not performed with the use of a uniform schedule. However, we have shown no effect of this factor on the treatment outcomes. Data on comorbidities and medications taken were obtained from internal and anaesthesiological consultation records prior to surgery. It was not possible to assess the duration of using the medications.

\section{Conclusions}

The use of ACEls may have a negative effect on long-term treatment outcomes in patients with ypN $+\mathrm{M} 0$ rectal cancer. In this group of patients, the NLN count seems to be an important prognostic factor, as well.

\section{List Of Abbreviations}

ACEls- angiotensin-converting enzyme inhibitors

AL- anastomotic leakage

AR- anterior resection

ARBs- angiotensin receptor blockers

BMI- body mass index

CAD- coronary artery disease

$\mathrm{CCl}$ - Charlson comorbidity index

CRT- chemoradiotherapy

Cl- confidence interval

DFS- disease-free survival 
DIAB- diabetes mellitus

DSS- disease-specific survival

ENE- extranodal extension

G- histological tumour grade

HR- hazard ratio

KKS- kallikrein-kinin system

LNR- lymph node ratio

LNY- lymph node yield

LODDS- log odds of positive lymph nodes

LVI- lymphovascular invasion

NLN- negative lymph node

OS- overall survival

PLN- positive lymph node

PNI- perineural invasion

RAS- renin-angiotensin system

RASI- renin-angiotensin system inhibitors

RT- radiotherapy

SD- standard deviation

TRG- tumour regression grade

\section{Declarations}

\section{Ethics approval and consent to participate}

This retrospective study involving human participants was in accordance with the ethical standards of the institutional research committee and with the 1964 Helsinki Declaration and its later amendments. The study was approved by the institutional ethics committee of National Research Institute of Oncology (KB/430-53/19). Due to the retrospective design of the study, the ethics committee confirmed that informed consent was not necessary from participants. 


\section{Consent for publication}

Not applicable

\section{Availability of data and materials}

The dataset supporting the conclusions of this article is included within the article (Additional file 1).

\section{Competing interests}

The authors declare that they have no competing interests

\section{Funding}

The authors have no financial or non-financial support to disclose

\section{Author's contributions}

MZ created the work concept and design, MZ, WS, PS, GH, DAW and DŻ participated in data collection, $M Z$ and WS participated in data analysis and interpretation, MZ wrote the manuscript, AC substantively revised the manuscript. All authors have read and approved the manuscript.

\section{Acknowledgements}

Not applicable

\section{References}

1. Kim HJ, Choi GS. Clinical Implications of Lymph Node Metastasis in Colorectal Cancer: Current Status and Future Perspectives. Ann Coloproctol. 2019 Jun;35(3):109-117.

2. Cui J, Zhang L, Yang L, Zhu YL, Fang H, Chen B, Ning Y, Zhang HZ. The prognostic significance of the treatment response of regional lymph nodes and the refinement of the current TNM staging system in locally advanced rectal cancer after neoadjuvant chemoradiotherapy. Cancer Med. 2020 Dec;9(24):9373-9384.

3. Li X, Lu H, Xu K, Wang H, Liang X, Hu Z. Negative lymph node count is an independent prognostic factor for patients with rectal cancer who received preoperative radiotherapy. BMC Cancer. 2017 Mar 28;17(1):227.

4. Kim HJ, Jo JS, Lee SY, Kim CH, Kim YJ, Kim HR. Low Lymph Node Retrieval After Preoperative Chemoradiation for Rectal Cancer is Associated with Improved Prognosis in Patients with a Good Tumor Response. Ann Surg Oncol. 2015;22(6):2075-81.

5. Kim JM, Park JW, Lee JH, Park YH, Park SJ, Cheon JH, Kim WH, Kim TI. Survival Benefit for Metformin Through Better Tumor Response by Neoadjuvant Concurrent Chemoradiotherapy in Rectal Cancer. Dis Colon Rectum. 2020 Jun;63(6):758-768. 
6. Morris ZS, Saha S, Magnuson WJ, Morris BA, Borkenhagen JF, Ching A, Hirose G, McMurry V, Francis DM, Harari PM, Chappell R, Tsuji S, Ritter MA. Increased tumor response to neoadjuvant therapy among rectal cancer patients taking angiotensin-converting enzyme inhibitors or angiotensin receptor blockers. Cancer. 2016 Aug 15;122(16):2487-95.

7. Allaix ME, Rebecchi F, Famiglietti F, Arolfo S, Arezzo A, Morino M. Long-term oncologic outcomes following anastomotic leak after anterior resection for rectal cancer: does the leak severity matter? Surg Endosc. 2019 Oct 15. DOI: 10.1007/s00464-019-07189-9.

8. Charlson ME, Pompei P, Ales KL, MacKenzie CR. A new method of classifying prognostic comorbidity in longitudinal studies: development and validation. J Chron Dis. 1987;40(5):373-83.

9. Rahbari NN, Weitz J, Hohenberger W, Heald RJ, Moran B, Ulrich A, Holm T, Wong WD, Tiret E, Moriya Y, Laurberg S, den Dulk M, van de Velde C, Büchler MW. Definition and grading of anastomotic leakage following anterior resection of the rectum: a proposal by the International Study Group of Rectal Cancer. Surgery. 2010 Mar;147(3):339-51.

10. Jang JH, Kim HC, Huh JW., Park YA, Cho YB, Yun SH, Lee WY, Yu JI, Park HC, Park YS, Park JO. Anastomotic leak does not impact oncologic outcomes after preoperative chemoradiotherapy and resection for rectal cancer. Ann Surg. 2019;269:678-685.

11. Sprenger T, Beißbarth T, Sauer R, Tschmelitsch J, Fietkau R, Liersch T, Hohenberger W, Staib L, Gaedcke J, Raab HR, Rödel C, Ghadimi M. Long-term prognostic impact of surgical complications in the German Rectal Cancer Trial CAO/ARO/AIO-94. Br J Surg. 2018 Oct;105(11):1510-1518.

12. Des Guetz G, Nicolas P, Perret GY, Morere JF, Uzzan B. Does delaying adjuvant chemotherapy after curative surgery for colorectal cancer impair survival? A meta-analysis. Eur J Cancer. 2010 Apr;46(6):1049-55.

13. Bosset JF, Calais G, Mineur L, Maingon P, Stojanovic-Rundic S, Bensadoun RJ, Bardet E, Beny A, Ollier JC, Bolla M, Marchal D, Van Laethem JL, Klein V, Giralt J, Clavère P, Glanzmann C, Cellier P, Collette L; EORTC Radiation Oncology Group. Fluorouracil-based adjuvant chemotherapy after preoperative chemoradiotherapy in rectal cancer: long-term results of the EORTC 22921 randomised study. Lancet Oncol. 2014 Feb;15(2):184-90.

14. Breugom AJ, van Gijn W, Muller EW, Berglund $\AA$, van den Broek CBM, Fokstuen T, Gelderblom H, Kapiteijn E, Leer JWH, Marijnen CAM, Martijn H, Meershoek-Klein Kranenbarg E, Nagtegaal ID, Påhlman L, Punt CJA, Putter H, Roodvoets AGH, Rutten HJT, Steup WH, Glimelius B, van de Velde CJH. Adjuvant chemotherapy for rectal cancer patients treated with preoperative (chemo)radiotherapy and total mesorectal excision: a Dutch Colorectal Cancer Group (DCCG) randomized phase III trial. Ann Oncol. 2015 Apr;26(4):696-701.

15. Turner JM, Kodali R. Should Angiotensin-Converting Enzyme Inhibitors ever Be Used for the Management of Hypertension? Curr Cardiol Rep. 2020 Jul 9;22(9):95.

16. Okwan-Duodu D, Landry J, Shen XZ, Diaz R. Angiotensin-converting enzyme and the tumor microenvironment: mechanisms beyond angiogenesis. Am J Physiol Regul Integr Comp Physiol. 2013 Aug 1;305(3):R205-15. 
17. da Costa PL, Sirois P, Tannock IF, Chammas R. The role of kinin receptors in cancer and therapeutic opportunities. Cancer Lett. 2014 Apr 1;345(1):27-38.

18. da Costa PLN, Wynne D, Fifis T, Nguyen L, Perini M, Christophi C. The kallikrein-Kinin system modulates the progression of colorectal liver metastases in a mouse model. BMC Cancer. $2018 \mathrm{Apr}$ 4;18(1):382.

19. Cheung KS, Chan EW, Seto WK, Wong ICK, Leung WK. ACE (Angiotensin-Converting Enzyme) Inhibitors/Angiotensin Receptor Blockers Are Associated With Lower Colorectal Cancer Risk: A Territory-Wide Study With Propensity Score Analysis. Hypertension. 2020 Sep;76(3):968-975.

20. Chen X, Yi CH, Ya KG. Renin-angiotensin system inhibitor use and colorectal cancer risk and mortality: A dose-response meta analysis. J Renin Angiotensin Aldosterone Syst. 2020 JulSep;21(3):1470320319895646.

21. Azoulay L, Assimes TL, Yin H, Bartels DB, Schiffrin EL, Suissa S. Long-term use of angiotensin receptor blockers and the risk of cancer. PLoS One. 2012;7(12):e50893.

22. Dierssen-Sotos T, Gómez-Acebo I, Palazuelos $C$, Rodriguez-Moranta F, Pérez-Gómez B, Fernández Vazquez JP, Amiano P, Barricarte A, Mirón-Pozo B, Tardon A, Capelo R, Peiro Pérez R, Huerta JM, Andreu M, Sierra MÁ, Castañón López C, Ruiz I, Moreno-lribas C, Olmedo-Requena R, Castaño-Vinyals G, Aragonés N, Kogevinas M, Pollán M, Llorca J. Relationship between drugs affecting the reninangiotensin system and colorectal cancer: The MCC-Spain study. Prev Med. 2017 Jun;99:178-184.

23. Rombouts AJ, Hugen N, Verhoeven RH, Kuiper JG, Poortmans PM, de Wilt JH, Nagtegaal ID. Is preoperative chemoradiation in rectal cancer patients modulated by ACE inhibitors? Results from the Dutch Cancer Registry. Radiother Oncol. 2019 Sep;138:86-92.

24. Ozawa T, Hashiguchi Y, Yagi T, Fukushima Y, Shimada R, Hayama T, Tsuchiya T, Nozawa K, linuma H, Ishihara S, Matsuda K. Angiotensin I-converting enzyme inhibitors/angiotensin II receptor blockers may reduce tumor recurrence in left-sided and early colorectal cancers. Int J Colorectal Dis. 2019 Oct;34(10):1731-1739.

25. Dai YN, Wang JH, Zhu JZ, Lin JQ, Yu CH, Li YM. Angiotensin-converting enzyme inhibitors/angiotensin receptor blockers therapy and colorectal cancer: a systematic review and meta-analysis. Cancer Causes Control. 2015 Sep;26(9):1245-55.

26. Cardwell CR, Mc Menamin ÚC, Hicks BM, Hughes C, Cantwell MM, Murray LJ. Drugs affecting the renin-angiotensin system and survival from cancer: a population based study of breast, colorectal and prostate cancer patient cohorts. BMC Med. 2014 Feb 13;12:28.

27. Persiani R, Biondi A, Gambacorta MA, Bertucci Zoccali M, Vecchio FM, Tufo A, Coco C, Valentini V, Doglietto GB, D'Ugo D. Prognostic implications of the lymph node count after neoadjuvant treatment for rectal cancer. Br J Surg. 2014 Jan;101(2):133-42.

28. Sun Y, Zhang Y, Huang Z, Chi P. Prognostic Implication of Negative Lymph Node Count in ypN + Rectal Cancer after Neoadjuvant Chemoradiotherapy and Construction of a Prediction Nomogram. J Gastrointest Surg. 2019 May;23(5):1006-1014. 
29. Zhang ZY, Gao W, Luo QF, Yin XW, Basnet S, Dai ZL, Ge HY. A nomogram improves AJCC stages for colorectal cancers by introducing CEA, modified lymph node ratio and negative lymph node count. Sci Rep. 2016 Dec 12;6:39028.

30. Yu L, Zhang XT, Guan SH, Cheng YF, Li LX. The Number of Negative Lymph Nodes is Positively Associated with Survival in Esophageal Squamous Cell Carcinoma Patients in China. Open Med (Wars). 2020 Mar 8;15:152-159.

31. He WZ, Xie QK, Hu WM, Kong PF, Yang L, Yang YZ, Jiang C, Yin CX, Qiu HJ, Zhang HZ, Zhang B, Xia LP. An increased number of negative lymph nodes is associated with a higher immune response and longer survival in colon cancer patients. Cancer Manag Res. 2018 Jun 18;10:1597-1604.

32. George S, Primrose J, Talbot R, Smith J, Mullee M, Bailey D, du Boulay C, Jordan H; Wessex Colorectal Cancer Audit Working Group. Will Rogers revisited: prospective observational study of survival of 3592 patients with colorectal cancer according to number of nodes examined by pathologists. Br J Cancer. 2006 Oct 9;95(7):841-7.

\section{Figures}




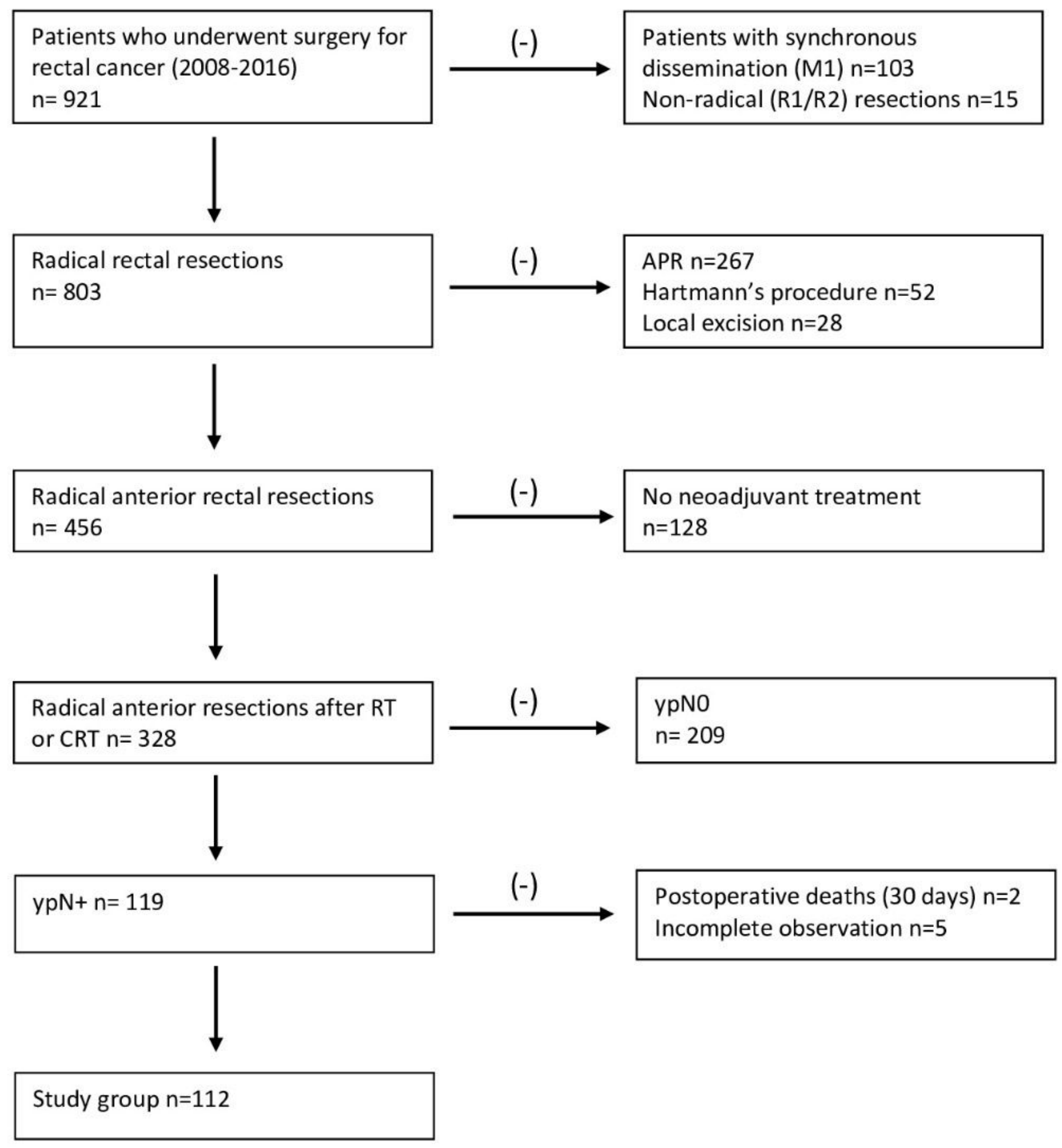

\section{Figure 1}

Process of study group formation 

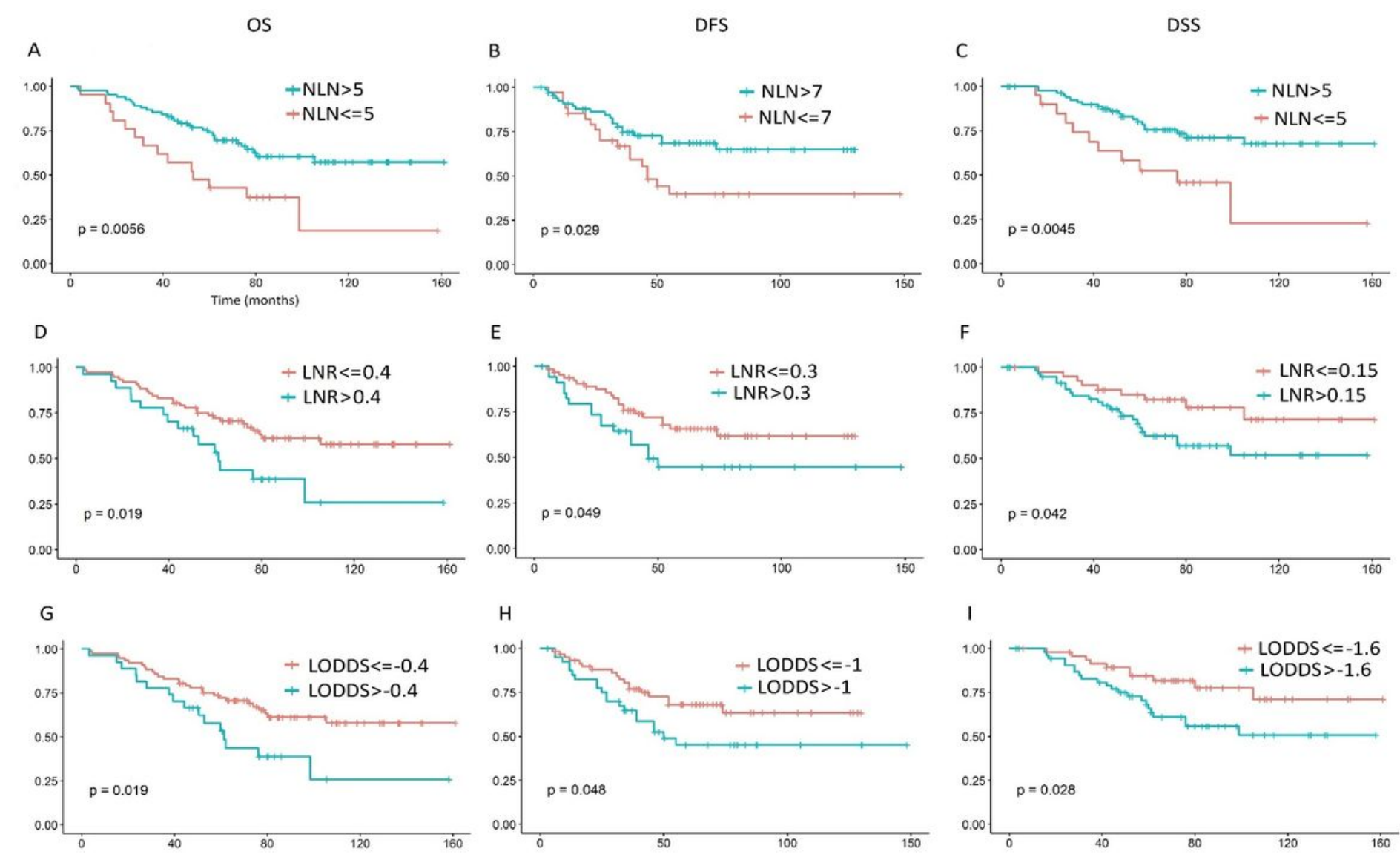

Figure 2

Survival analysis (OS, DFS and DSS) depending on negative lymph node count (A-C), lymph node ratio (D-F) and log odds of positive lymph nodes (G-I). 
A

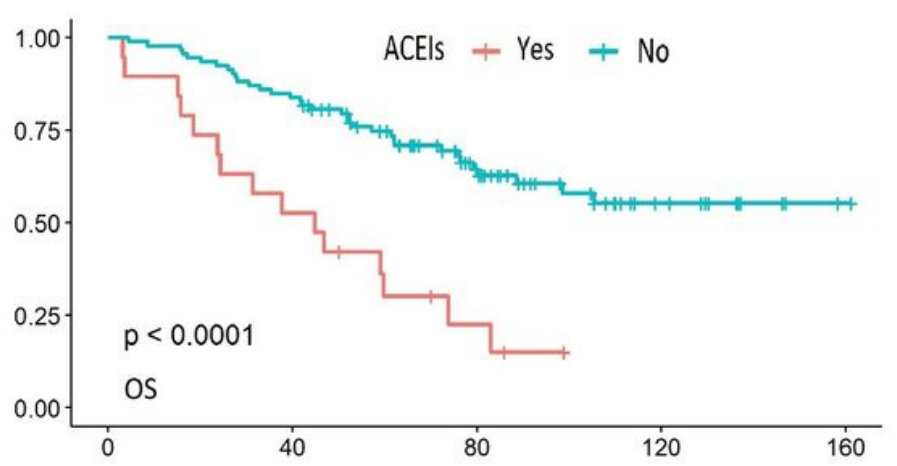

C

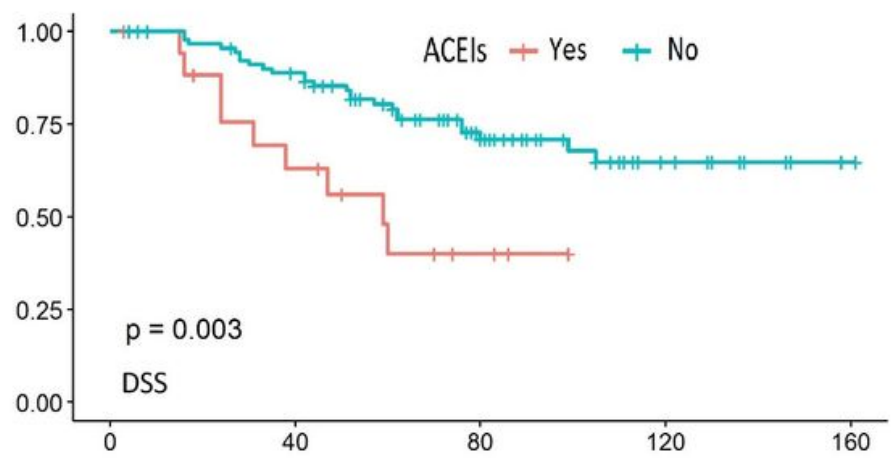

B

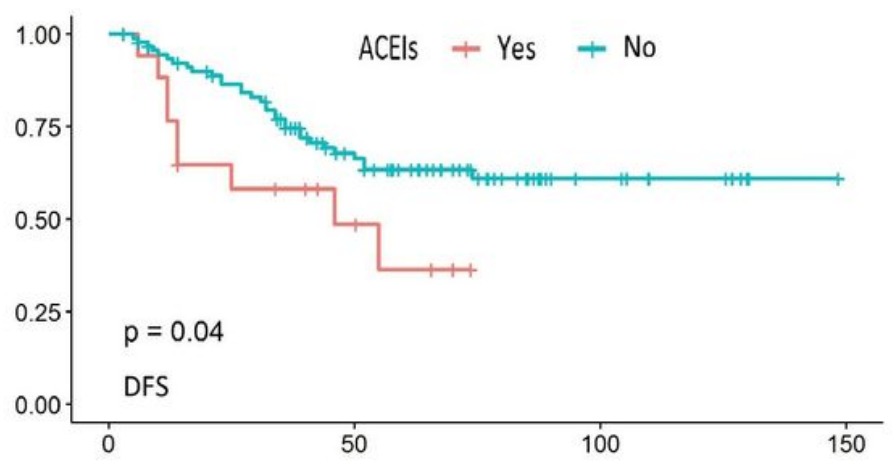

D

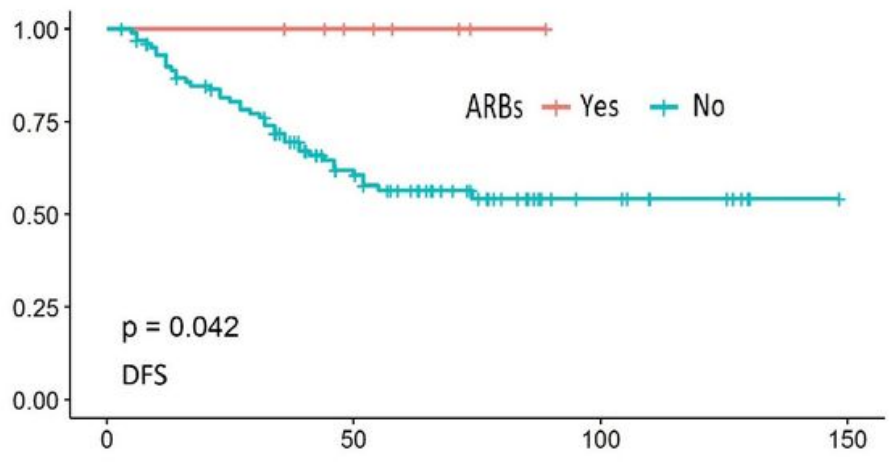

Figure 3

Survival analysis (OS, DFS and DSS) of patients depending on angiotensin-converting enzyme inhibitors $(A-C)$ and DFS depending on angiotensin receptor blockers (D).

\section{Supplementary Files}

This is a list of supplementary files associated with this preprint. Click to download.

- Supplementaryfile1dataset.xlsx 